\title{
The Influence of Plasticizers on Determination of Cationic Surfactants in Pharmaceutical Disinfectants by Direct Potentiometric Surfactant Sensor ${ }^{\dagger}$
}

\author{
Maja Karnaš ${ }^{1}$, Marija Jozanović ${ }^{2, *}$, Bojan Đurin ${ }^{3}$ and Nikola Sakač ${ }^{4, *}$ \\ 1 Faculty of Agrobiotecnical Sciences Osijek, Josip Juraj Strossmayer University of Osijek, Osijek, Croatia; \\ maja.karnas@fazos.hr \\ 2 Department of Chemistry, Josip Juraj Strossmayer University of Osijek, Osijek, Croatia \\ 3 Department of Civil Engineering, Center Varaždin, University North, Croatia; bdjurin@unin.hr \\ 4 Faculty of Geotechnical Engineering, University of Zagreb, Varaždin, Croatia \\ * Correspondence: mjozanovic@kemija.unios.hr (M.J.); nsakac@gfv.unizg.hr (N.S.); Tel.: +385-42-408-907 \\ (N.S.) \\ + Presented at the 7th Electronic Conference on Sensors and Applications, 15-30 November 2020; Available \\ online: https://ecsa-7.sciforum.net/.
}

Published: 15 November 2020

\begin{abstract}
Ion selective liquid membrane type membranes are usually made of a PVC, ionophore and a plasticizer. Plasticizers soften the PVC but due to their liphopilicity they influence the ionophore, the ion exchange across the membrane, membrane resistance and consequently the analytical signal. The aim of the research was to investigate the influence of 4 different plasticizers, in formulation with the same ionophore, on the analytical properties of the sensor membrane towards two often used cationic surfactants, then select the best membrane formulation and test it on real samples of six pharmaceutical disinfectants containing cationic surfactants.
\end{abstract}

Keywords: cationic surfactant; surfactant sensor; plasticizer; pharmaceutical disinfectants

\section{Introduction}

Surface active agents or surfactants are widely used in household and industry for washing, cleaning, disinfection and as emulsifiers. There are four main groups of surfactants: anionic, cationic, amphoteric and nonionic. Cationic surfactants are used in broad spectra of commercial products as preservatives and disinfectants Since classical methods for determination of lower surfactant concentrations [1] have many disadvantages, direct potentiometric sensors for surfactants based on ion selective electrodes with liquid membrane type [2,3] offer an elegant, affordable and reliable substitution. Liquid membrane type sensing membranes are typically based on high molecular weight PVC mixed with plasticizer and an ionophore [4]. Even though the plasticizer has a function to soften the matrix and make it more flexible, it also has an influence on the final direct potentiometric sensor response [5] since in influences the membrane polarity, resistance, ion mobility across the membrane [6,7]. The typical weight ratio of PVC to plasticizer is $1: 2$, with up to 1 wt \% ionophore, respectively. Higher amounts of plasticizer could be interfering to the measurement [8]. Previously we synthesized 1,3-didecyl-2-methylimidazolium-tetraphenylborate (DMI-TPB) ion pair (ionophore), implement it in the PVC-based liquid membrane surfactant sensor and used it for cationic surfactants quantification in real samples [9].

In this paper we selected four different plasticizers and implement them in the PVC-based sensing membrane with DMI-TPB as an ionophore to observe the plasticizer influence on the response characteristics of the direct potentiometric surfactant sensor and test the selected membrane formulation on commercial pharmaceutical disinfectants. 


\section{Materials and Methods}

\subsection{Membrane Preparation and Surfactant Sensor Fabrication}

Four different plasticizers were used to manufacture ISE membranes: o-nitrophenyl octyl ether (P1), bis(2-ethylhexyl) phthalate (P2), bis(2-ethylhexyl) sebacate (P3) and dibutyl sebacate (P4); all from Sigma Aldrich, Germany. The membranes were prepared by dissolving 1,3-didecyl-2methylimidazolium-tetraphenylborate (DMI-TPB) ion pair in small amount of tetrahydrofuran (THF) (Fluka Switzerland). Next the high-molecular-weight PVC (Fluka Switzerland) and corresponding plasticizer were nixed. To this mixture we added previously prepared mixture of ion pair/THF and all was transferred to the ultrasonic bath (Sonoplus Ultrasonic homogenizer with a horn sonicator HD 3100, from Bandelin, Germany) for sonication. The mixture was transferred to $24 \mathrm{~mm}$ OD mold glass ring. After two days the THF evaporated and the thin plasticized layer was cut in $7 \mathrm{~mm}$ OD discs (sensor membranes) and stored dry for later use. The same procedure was used for each plasticizer separately. Phillips electrode body (Phillips IS 561, Glasblaeserei Moeller, Switzerland) with 3M sodium chloride (Sigma Aldrich, Germany) inner electrolyte was used to incorporate prepared sensor membranes.

\subsection{Surfactant Sensor Response Measurements}

Response measurements for cationic surfactants cetylpyridinium chloride (CPC) and cetrimonium bromide (CTAB), both from Sigma Aldrich, Germany, were performed for each membrane with corresponding plasticizer formulation. Instrumentation for direct potentiometric response measurements was a Metrohm $780 \mathrm{pH}$ meter and a Metrohm 794 Basic Titrino with stirrer (Metrohm, Switzerland) and a silver/silver chloride reference electrode (Metrohm, Switzerland) paired with fabricated surfactant sensor. The measurement was performed in deionized water by adding corresponding increments of sodium dodecyl sulfate (DS) $\left(4 \times 10^{-2} \mathrm{M}\right.$ to $\left.4 \times 10^{-4} \mathrm{M}\right)$ to cover the broad concentration range. The increment interval was from $120 \mathrm{~s}$ (for lower concentrations) to $60 \mathrm{~s}$ for higher DS concentrations.

\subsection{Direct Potentiometric Titrations}

Direct potentiometric titrations of $\mathrm{CPC}$ or $\mathrm{CTAB}$ were performed with corresponding concentration of DS. A Metrohm 808 Titrando titrator with magnetic stirrer and Tiamo 2.1 software (Metrohm, Switzerland) connected to silver/silver chloride electrode (Metrohm, Switzerland) paired with a corresponding surfactant sensor electrode, were used to perform direct potentiometric titrations. The measuring volume was $25 \mathrm{~mL}(20 \mathrm{~mL}$ deionized water and $5 \mathrm{~mL}$ of corresponding surfactant solution). The concentrations of cationic surfactant solutions were $4 \times 10^{-3} \mathrm{M}$. The titrations of commercial pharmaceutical disinfectants provided in the local drug sore, were performed by the same procedure for selected membrane, with $\mathrm{pH}$ adjustment to avoid false result due to the amphoteric surfactants present in formulation.

\section{Results and Discussion}

\subsection{Response Characterization}

The influence of plasticizer type on the response characteristics of the DMI-TPB sensor was tested on two cationic surfactants, CPC and CTAB (Figure 1), in five independent series for each. Four different plasticizers were tested (P1-P4). Cationic surfactants $\mathrm{CPC}$ and $\mathrm{CTAB}$ were selected since they are often used in commercial product formulations.

The response curves for all plasticizers showed slight distortions when the concentrations of both, $\mathrm{CPC}$ and $\mathrm{CTAB}$, were higher, due to the micelle formation. 
(a)
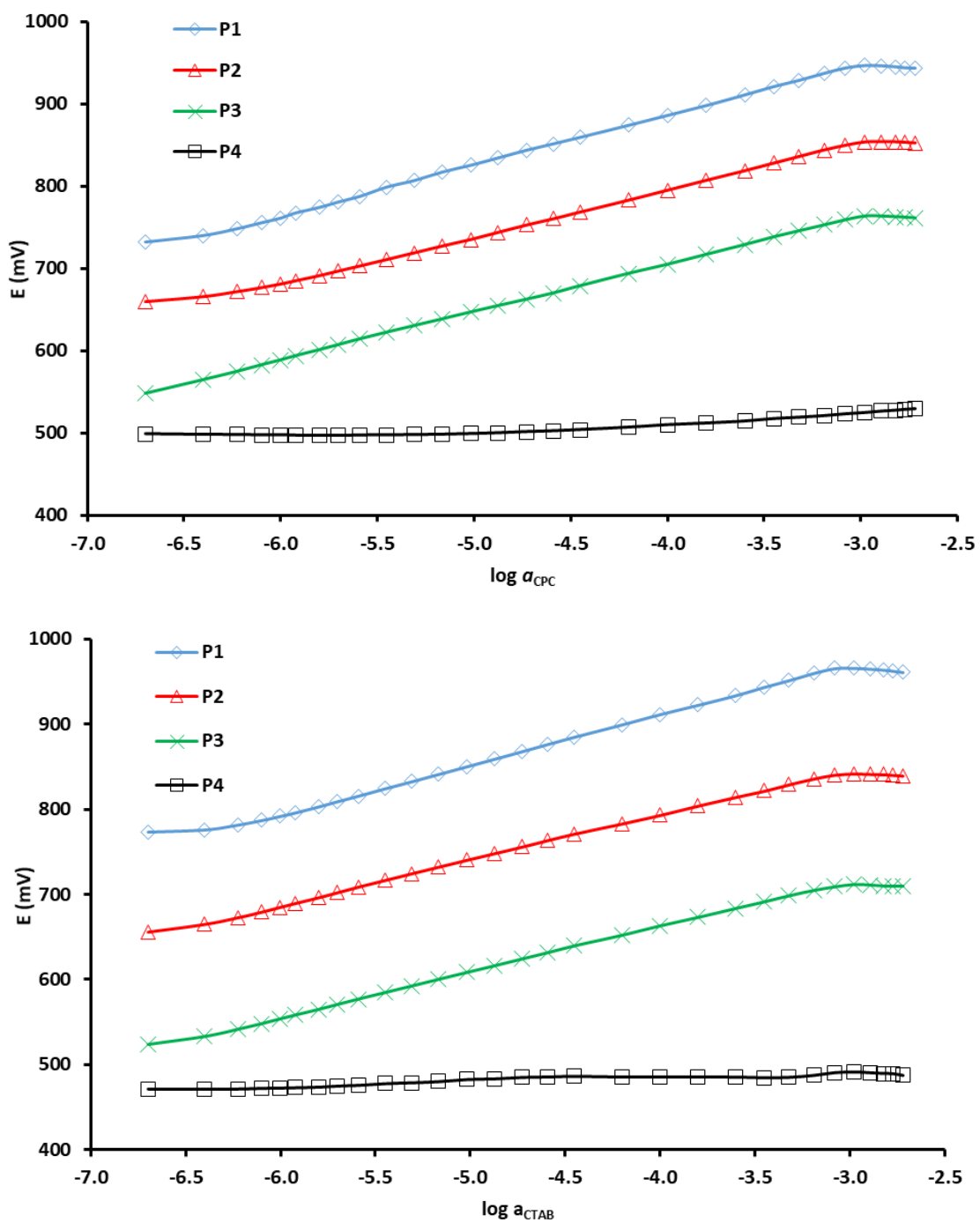

(b)

Figure 1. Influence of the plasticizer type on the DMI-TPB surfactant sensor response characteristics toward cationic surfactants: (a) CPC and (b) $\mathrm{CTAB}$, in deionized water. Plasticizers, from top to bottom: 2-nitrophenyl octyl ether (P1), bis(2-ethylhexyl) phthalate (P2), bis (2-ethylhexyl) sebacate (P3), and dibutyl sebacate (P4). The curves have been shifted vertically for clarity.

The response curves for CPC in deionized water were shown in Figure 1a. The slope values for plasticizers P1 was the closest to the Nernstian, $57.9 \pm 0.4$, while the plasticizers P4 obtained the lowest slope value, $12.80 \pm 0.2$. Correlation coefficients for all four plasticizers were approximately 0.99 , within the useful linear concentration range. Plasticizer 3 obtained the highest useful concentration range from $1.3 \times 10^{-3}$ to $2 \times 10^{-7} \mathrm{M}$, while plasticizer 4 obtained a very low potential change trough all investigated concentrations. The response curves for CTAB in deionized water are shown in Figure $1 \mathrm{~b}$. The slope vales for plasticizers P1 was the closest to the Nernstian, $60.0 \pm 0.7$, while the plasticizers P4 obtained the lowest slope value. Correlation coefficients for all four plasticizers were approximately 0.99 , within the useful linear concentration range. Plasticizers 2 and 3 obtained the highest useful concentration range from $1 \times 10^{-3}$ to $4 \times 10^{-7} \mathrm{M}$, while plasticizer 4 obtained a very low potential change trough all investigated concentrations.

\subsection{Direct Potentiometric Titrations}

The main applications of the surfactant sensors are end-point indications during surfactant direct potentiometric titrations. Two cationic surfactants, CPC and DBS, were determined by direct potentiometric titrations with DMI-TPB surfactant sensor containing formulations of four different plasticizers (P1-P4). The standard DS solution $\left(\mathrm{c}=4 \times 10^{-3} \mathrm{M}\right)$ was used for direct potentiometric 
titrations of $\mathrm{CPC}\left(\mathrm{c}=4 \times 10^{-3} \mathrm{M}\right)$ and $\mathrm{CTAB}\left(\mathrm{c}=4 \times 10^{-3} \mathrm{M}\right)$. The corresponding potentiometric titration curves were presented in Figure 2.

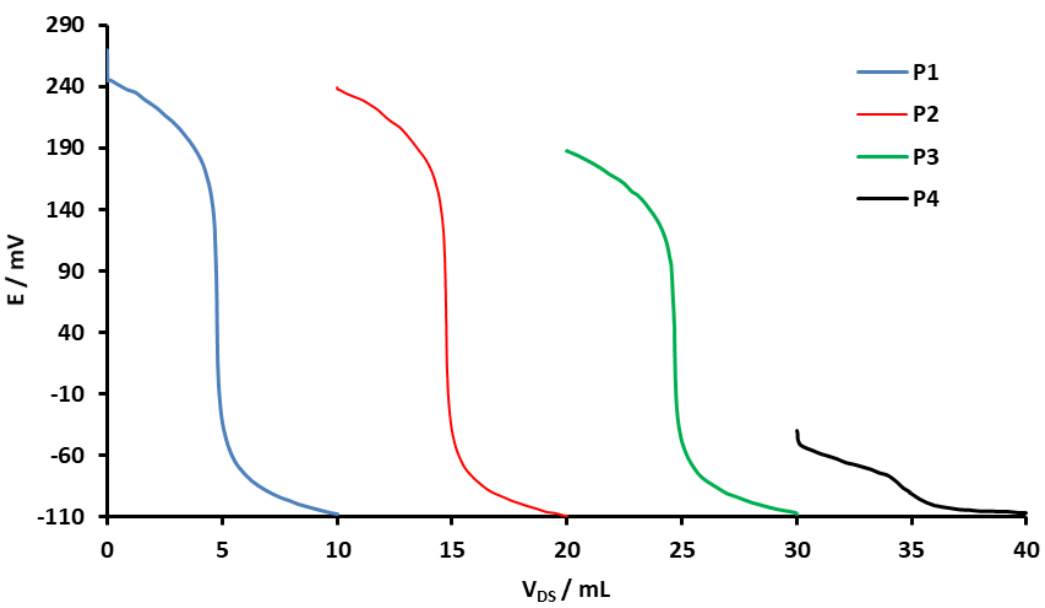

(a)

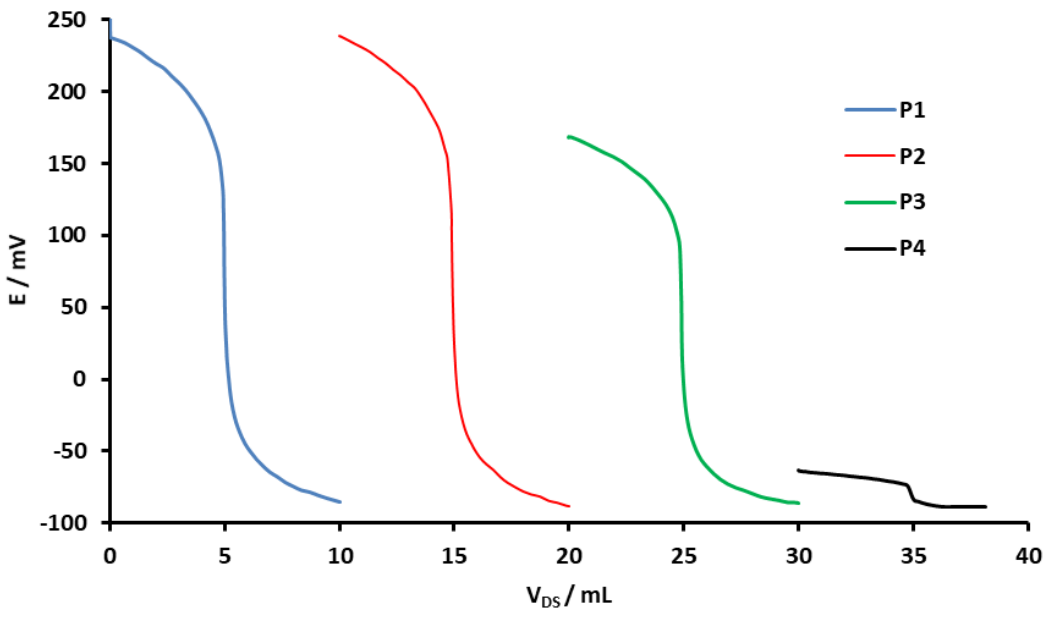

(b)

Figure 2. Direct potentiometric titration curves for (a) CPC $\left(\mathrm{c}=4 \times 10^{-3} \mathrm{M}\right)$ and (b) CTAB; with DS $\left(c=4 \times 10^{-3} \mathrm{M}\right)$ obtained by the use of DMI-TPB sensor and for different plasticizers, from left to right: 2-nitrophenyl octyl ether (P1), bis(2-ethylhexyl) phthalate (P2), bis (2-ethylhexyl) sebacate (P3) and dibutyl sebacate (P4).

The titration curves of CPC $\left(\mathrm{c}=4 \times 10^{-3} \mathrm{M}\right)$ with DS $\left(\mathrm{c}=4 \times 10^{-3} \mathrm{M}\right)$, using DMI-TPB sensors containing four different plasticizers, exhibited well-defined and sharp inflexion points (Figure 2a). Only the sensor membrane containing the P4 plasticizer obtained small signal change, but still with potential jump at expected equivalence point volume values. This was expected due to low slope exhibited for P4 formulation shown in Figure 1a. The highest value of potential change at the endpoint was demonstrated by the sensor containing P1 plasticizer.

The titration curves of CTAB $\left(c=4 \times 10^{-3} \mathrm{M}\right)$ with DS $\left(\mathrm{c}=4 \times 10^{-3} \mathrm{M}\right)$, using DMI-TPB sensors containing four different plasticizers, exhibited well-defined and sharp inflexion points (Figure $2 b$ ). Only the sensor membrane containing the P4 plasticizer obtained small signal change, but still with better than obtained for CPC in Figure 2a. The highest value of potential change at the end-point were demonstrated by the sensors containing P1 and P2 plasticizer.

\subsection{Titration of Pharmaceutical Disinfectants}

The DMI-TPB sensor containing plasticizer P1 was selected as an end-point indicator in potentiometric titration of cationic surfactants in six commercial pharmaceutical disinfectants since it presented the best characteristic. The standard solution of anionic surfactant DS $\left(c=4 \times 10^{-3} \mathrm{M}\right)$ was 
used as a titrant. PVC liquid membrane Direct Potentiometric Surfactant Sensor (DPSS) was used as a reference [10]. For determinations in six disinfectant samples, no significant differences were observed between the means of both the DMI-TPB sensor containing plasticizer P1 and the DPSS at the $95 \%$ confidence level. A sufficient well agreement was observed for all results (Table 1).

Table 1. The results of potentiometric titrations of cationic surfactants in pharmaceutical disinfectants by DS ( $\mathrm{c}=4 \mathrm{mM})$ as titrant and a DMI-TPB sensor containing plasticizer P1 as an indicator, in comparison with the results obtained with referent Direct Potentiometric Surfactant Sensor (DPSS).

\begin{tabular}{ccccc}
\hline \multirow{2}{*}{ Product } & \multicolumn{3}{c}{ ANIONIC SURFACTANT CONTENT ${ }^{\mathbf{1}}$} \\
\cline { 2 - 5 } & DMI-TPB Sensor with P1 & \multicolumn{2}{c}{ DPSS $^{2}$} \\
\cline { 2 - 5 } \% & RSD (\%) & \% & RSD (\%) $^{\text {\% }}$ \\
\hline A & 4.3223 & 0.91 & 4.2483 & 0.93 \\
B & 5.1313 & 0.62 & 5.3013 & 0.64 \\
C & 4.7646 & 0.72 & 4.7021 & 0.67 \\
D & 4.7222 & 0.88 & 4.5819 & 0.93 \\
E & 0.0684 & 0.35 & 0.0672 & 0.36 \\
F & 0.1494 & 0.25 & 0.1502 & 0.27 \\
\hline
\end{tabular}

${ }^{1}$ Average of 5 determinations. ${ }^{2}$ DPSS described in ref. [10].

\section{Conclusions}

Four different plasticizers were incorporated into the PVC-based liquid membrane surfactant sensors with DMI-TPB as an ionophore. Membranes were characterized by their response on cationic surfactant $\mathrm{CPC}$ and $\mathrm{CTAB}$, and direct potentiometric titrations of $\mathrm{CPC}$ and $\mathrm{CTAB}$ with anionic surfactant DS as a titrant. Sensor membrane containing plasticizer 2-nitrophenyl octyl ether (P1) showed the best properties and was used for titration of six pharmaceutical disinfectants obtained from the local store. The results of showed good agreement with conventional reference direct potentiometric sensor developed previously by the same group.

Author Contributions: Conceptualization, N.S. and M.J.; methodology, N.S., M.J.; validation, N.S. and M.K.; investigation, M.K.; data curation, N.S. and B.Đ.; writing-original draft preparation, N.S., M.J. and B.Đ.; writing - review and editing, N.S. and M.J.; visualization, M.K. and B.Đ.; supervision, N.S. All authors have read and agreed to the published version of the manuscript.".

Conflicts of Interest: The authors declare no conflict of interest.

\section{References}

1. Frend, A.J.; Moody, G.J.; Thomas, R.; Birch, B.J. Flow injection analysis with tubular membrane ionselective electrodes in the presence of anionic surfactants. Analyst 1983, 108, 1357-1364, doi:10.1039/AN9830801357.

2. Sakač, N.; Jozanović, M.; Karnaš, M.; Sak-Bosnar, M. A New Sensor for Determination of Anionic Surfactants in Detergent Products with Carbon Nanotubes as Solid Contact. J. Surfactants Deterg. 2017, 1-9, doi:10.1007/s11743-017-1978-0.

3. Sak-Bosnar, M.; Madunić-Čačić, D.; Sakač, N.; Galović, O.; Samardžić, M.; Grabarić, Z. Potentiometric sensor for polyethoxylated nonionic surfactant determination. Electrochim. Acta 2009, 55, 528-534, doi:10.1016/j.electacta.2009.09.010.

4. Zareh, M.M. Blank membranes versus ionophore-based membranes for the selective determination of $\mathrm{H}^{+}$. Anal. Sci. 2009, 25, 1131-1135, doi:10.2116/analsci.25.1131.

5. Guilbault, J.D.R.T.G.G.; Durst, R.A.; Frant, M.S.; Freiser, H.; Hansen, E.H.; Light, T.S.; Pungor, E.; Rechnitz, G.; Rice, N.M.; Rohm, T.J.; et al. Recommendations for nomenclature of ion-selective electrodes. Pure Appl. Chem. 1976, 48, 127-132.

6. Karnaš, M.; Sakač, N.; Jozanović, M.; Tsakiri, M.; Kopriva, M.; Kovač Andrić, E.; Sak Bosnar, M. The influence of plasticisers on response characteristics of anionic surfactant potentiometric sensor. Int. J. Electrochem. Sci. 2017, 12, 5921-5933, doi:10.20964/2017.07.16. 
7. Zahran, E.M.; New, A.; Gavalas, V.; Bachas, L.G. Polymeric plasticizer extends the lifetime of PVCmembrane ion-selective electrodes. Analyst 2014, 139, 757-763, doi:10.1039/c3an01963b.

8. Carey, C. Plasticizer Effects in the PVC Membrane of the Dibasic Phosphate Selective Electrode. Chemosensors 2015, 3, 284-294, doi:10.3390/chemosensors3040284.

9. Madunić Čačić, D.; Sak-Bosnar, M.; Galović, O.; Sakač, N.; Matešić-Puač, R. Determination of cationic surfactants in pharmaceutical disinfectants using a new sensitive potentiometric sensor. Talanta 2008, 76, 259-264, doi:10.1016/j.talanta.2008.02.023.

10. Sakač, N.; Karnaš, M.; Jozanović, M.; Medvidović-Kosanović, M.; Martinez, S.; Macan, J.; Sak-Bosnar, M. Determination of anionic surfactants in real samples using a low-cost and high sensitive solid contact surfactant sensor with MWCNTs as the ion-to-electron transducer. Anal. Methods 2017, 9, 2305-2314, doi:10.1039/C7AY00099E.

(C) 2020 by the authors. Submitted for possible open access publication under the terms and conditions of the Creative Commons Attribution (CC BY) license (http://creativecommons.org/licenses/by/4.0/). 